\title{
KUIDAS TUVASTADA DIALOOGI STRUKTUURI: KORPUSE ANALÜÜS
}

\author{
Mare Koit
}

Ülevaade. Artiklis uuritakse dialoogi kui erilist sidustekstide liiki, eesmärgiga määrata dialoogi struktuur, mille moodustavad mikrotaseme üksused - dialoogiaktid. Empiiriliseks materjaliks on väike telefonimüügivestluste alamkorpus. Analüüsitavates kõnedes suhtlevad omavahel kaks ametiisikut: helistaja (koolitusfirma konsultant) pakub koolituskursusi, mida eeldatavasti vajab vastuvõtja (teise asutuse esindaja). Dialoogisalvestused on litereeritud, kasutades vestlusanalüüsi transkriptsiooni. Korpuses on märgendatud dialoogiaktid. Artiklis otsitakse reegleid, mis võimaldaksid automaatselt tuvastada müügivestluse erinevaid faase, kasutades selleks dialoogiaktide järjendeid ja nende positsiooni dialoogis. Edasine eesmärk on luua tarkvara dialoogide automaatseks pragmaatiliseks analüüsiks, sh dialoogiaktide, dialoogide lineaarse struktuuri ja alamdialoogide tuvastamiseks. ${ }^{*}$

Võtmesõnad: dialoog, müügivestlus, dialoogi struktuur, dialoogiakt, eesti keel

\section{Sissejuhatus}

Sidusteksti pragmaatiline analüüs on üks keele automaattöötluse ülesandeid. Lausungite ja nende tähenduste vaheliste seoste ning lausungi eesmärgi leidmiseks saab kasutada erinevat informatsiooni. Kui eelnevalt on läbi viidud teksti morfoloogiline, süntaktiline ja/või semantiline analüüs, siis on nende etappide väljund rikkalikuks sisendiks pragmaatilisele analüsaatorile (Barton 2004). Sellisel juhul saab sõnastada reeglid, mis võtavad arvesse eelnenud analüüsietappide infot. Teisalt, kui on olemas mahukas dialoogikorpus, siis saab kasutada andmepõhiseid meetodeid, et määrata diskursuse struktuuri ja uurida suhtlemisel kasutatavat keelt.

Käesolevas artiklis uuritakse sidustekstide eriliiki - dialooge. Dialoogi analüüsimiseks tuleb see jaotada väiksemateks struktuuri-ja funktsionaalseteks üksusteks

Artikli valmimist on toetanud Euroopa Regionaalarengufond Eesti Arvutiteaduse Tippkeskuse kaudu, Haridusja Teadusministeerium (projektid SF0180078s08 ja EKT5) ning Eesti Teadusagentuur (grandid ETF9124 ja ETF8558). Autor tänab Riina Kasterpalu asjatundlike märkuste eest. 
(Gibbon jt 2000). Siinseks eesmärgiks on määrata dialoogi struktuur, mille moodustavad mikrotaseme üksused - dialoogiaktid ja nende järjendid.

Dialoogi struktuuri on vaja teada inimesega loomulikus keeles suhtlevate dialoogsüsteemide arendamisel. Dialoogihalduril peab olema info suhtluse ülesehitusest, selleks et mõista kasutaja lausungeid ja kavandada oma vastuseid (Lester jt 2004). Teiselt poolt võib dialoogi struktuuri tuvastamist käsitleda ka omaette ülesandena, mille lahendamise tulemusi saab kasutada erinevates rakendustes, nt sisukokkuvõtete koostamine, infootsing jne.

Artiklis uuritakse institutsionaalsete dialoogide ühte liiki - autentseid müügivestlusi. Ühe koolitusfirma konsultandid helistavad võimalikele klientidele - teiste asutuste juhtidele või personalispetsialistidele - ja pakuvad asutuse töötajatele koolituskursusi. Eesmärgiks on tutvustada koolitusfirmat, koguda infot kliendi kohta, äratada temas huvi kursuste vastu, põhjendada kursuste kasulikkust ja toetada klienti positiivse otsuse tegemisel (s.o tellida koolitusfirmast mõni kursus).

Artikli ülesehitus on järgmine. Jaotises 2 antakse ülevaade empiirilisest materjalist - Eesti dialoogikorpusest ja korpuse märgendamisel kasutatavast dialoogiaktide tüpoloogiast. Jaotis 3 on pühendatud korpuse analüüsile. Vaadeldakse müügivestluse erinevaid faase. Jaotises 4 arutletakse korpuse analüüsi tulemuste üle ja jaotises 5 tehakse kokkuvõtteid.

\section{Korpus ja dialoogiaktide tüpoloogia}

Uurimus põhineb Eesti dialoogikorpusel (EDiK) (Hennoste jt 2009). Selle suurima osa moodustavad inimestevahelised dialoogid, mis on võetud Eesti suulise keele korpusest - 1137 telefonikõnet (infotelefonile, reisibüroodesse, müügivestlused jne) ja 45 silmast-silma vestlust, kokku 1182 transkribeeritud teksti mahuga 250000 tekstisõna.

Teise osa EDiK-ist moodustavad umbes 200 kirjalikku dialoogi, mis on kogutud arvutisimulatsioonides võlur Ozi meetodil.

EDiK-i kolmandat osa (inimese ja arvuti vahelised vestlused) kogutakse kahe veebipõhise dialoogsüsteemi vahendusel, mis suhtlevad kasutajaga eesti keeles. Üks neist annab infot Tartu kinodes linastuvate filmide kohta ja teine hambaraviinfot.

Korpuses on märgendatud dialoogiaktid (DA), kasutades Tartu Ülikoolis väljatöötatud aktitüpoloogiat (Hennoste, Rääbis 2004). Tüpoloogia põhiosa on sarnane üldtuntud tüpoloogiatega (nt DAMSL ja SWBD-DAMSL). Tüpoloogia põhineb vestlusanalüüsist pärit suhtluse organiseerimise printsiipidel (Hutchby, Wooffitt 1998), mille kohaselt peab partner alati reageerima eelmisele voorule, sõltumata sellest, millised on tema oma plaanid või strateegiad. Mõned DA-de klassid moodustavad kokkuleppelisi paare, kus esimese akti lausumine teeb relevantseks teise akti. Selliseid seotud aktipaare nimetatakse naabruspaarideks (nt küsimus-vastus). Tüpoloogias on aktid jaotatud kahte klassi: naabruspaariaktid ja üksikaktid. Igal naabruspaariaktil on esiliige ja järelliige (vrd edasivaatav ja tagasivaatav funktsioon DAMSL-is).

Kõik DA-d on jaotatud infoaktideks (küsimused, direktiivid jms) ja suhtluse juhtimise aktideks (rituaalsed aktid, tagasiside jms). Suhtluse juhtimise aktid on omakorda jaotatud kahte alamrühma: aktid, mis juhivad sujuvat suhtlust, ja suhtlusprobleemide lahendamise aktid (e parandusaktid). 
Tüpoloogias on 12 rühma; DA-de koguarv on 126.

DA-de nimed koosnevad kahest osast, mis on teineteisest eraldatud kooloniga: a) esimesed kaks tähte annavad aktirühma nime, nt KY - küsimused, vR - vabatahtlikud reaktsioonid. Kolmas täht esineb ainult naabruspaariaktide nimes - esiliige (E) või järelliige (J); b) akti pärisnimi, nt KYE: AVATUD, KYJ: INFO ANDMINE, VR: VASTUVÕTUTEADE (vt lähemalt Hennoste, Rääbis 2004).

Dialoogiakte on seni märgendatud käsitsi, kasutades tarkvara, mis hõlbustab tekstide valikut korpusest ja DA-de valikut menüüst. Kaks lingvisti märgendavad sama teksti teineteisest sõltumatult ja kolmas ühtlustab märgenduse. Praeguseks on kasutamisvalmis ka veebipõhine tarkvara DA-de poolautomaatseks märgendamiseks (Aller 2012). Programmi sisendiks on dialoogi tekst, programm tükeldab selle lausungiteks ja määrab igale lausungile kuni viis aktimärgendit, kasutades Bayesi naiivset klassifitseerijat. Seejärel saab inimene nende hulgast valida õige(d) aktimärgendi(d) või lisada menüüst uue(d) märgendi(d), kui programmi leitud märgendite hulgas ei olnud õiget.

Järgnevas dialoogikatkendis (1) on osalejateks klient $(A)$ ja ametnik $(B)$. Telefonikõne on lindistatud ja litereeritud, kasutades vestlusanalüüsi transkriptsiooni. DA-d on märgendatud.

(1) A: tere? | RIE: TERVITUS |

kas te ütleksite (.) doktor `Kullassepa `telefoninumbri. | KYE: JUTUSTAV KAS |

(...)

B: kaheksakend `neli kuus seitse kaheksa. | KYJ: INFO ANDMINE |

A: kaheksakend neli kuus seitse kaheksa | KYE: VASTUST PAKKUV |

| PPE: ÜLEKÜSIMINE |

[ai]täh | RIE: TÄNAN |

B: [jah] | KYJ: JAH | | PPJ: PARANDUS |

palun? | RIJ: PALUN |

Käesoleva uurimuse jaoks valiti EDiK-i suletud alamkorpus, mis koosneb telefoni teel peetud müügivestlustest (Rääbis, Vellerind 2000). Telefonikõnedes suhtlevad kaks ametiisikut, kellest üks, helistaja (konsultant), esindab koolitusfirmat (näidetes on firma muudetud nimi Tiritamm), mis pakub koolitust neljas valdkonnas: juhtimine, müük, turundus ja teenindus. Pakutavad kursused on eeldatavasti vajalikud teisele ametiasutusele, kelle esindajat nimetatakse siin kliendiks. Dialoogid on korpuse kinnises osas, vastavalt kokkuleppele koolitusfirmaga. Publitseerida on lubatud üksnes dialoogide katkendeid, maksimaalse pikkusega neli vooru. Kogu korpuses on 48 telefonikõnet (kõned on salvestanud ja litereerinud Riina VellerindKasterpalu ning DA-d on märgendatud TÜ suulise keele rühmas). Käesolevas artiklis on müügivestluste hulgast juhuslikult valitud analüüsimiseks 9 kõnet.

Korpuses on küll märgendatud DA-d, kuid see on morfoloogiliselt ja süntaktiliselt analüüsimata. Siiski osutub, et ka DA-de märgendid annavad piisavaid märguandeid dialoogi struktuuri tuvastamiseks. 


\section{Müügivestluste analüüs}

\subsection{Vestluse üldine struktuur}

Kõik korpuse müügivestlused kuuluvad läbirääkimiste algusetappi. Analüüsitud kõnedes helistab konsultant võimalikule kliendile pärast seda, kui on saatnud talle koolitusfirma kataloogi, mis sisaldab pakutavate kursuste ja koolitusprogrammide nimestiku ning hinna. Telefonikõne kestel annab helistaja infot oma firma kohta, et tekitada ja/või suurendada kliendi huvi kursuste vastu. Saamaks infot kliendi vajadustest, esitab helistaja talle palju küsimusi. Reeglina on konsultandil vaja pidada mitu kõnelust, enne kui klient teeb kursuste kohta otsuse. Otsus võib olla nii positiivne (s.t tellida mõni kursus) kui ka negatiivne (s.t lükata tagasi konsultandi ettepanekud). Suur osa kõnedest lõpeb siiski kokkuleppega hoida kontakti, mis tähendab, et kõne jooksul ei jõua klient küll otsusele, aga on valmis vestlema samal teemal edaspidi.

Müügivestlus nagu iga teinegi dialoog kujutab endast nn transaktsiooni, milles esinevad sellised hierarhilised tasemed nagu vooruvahetused, mis omakorda koosnevad voorudest ja DA-dest. Müügivestluse üldine lineaarne struktuur (s.o vestluse kui voorude ja lausungite järjendi liigendus osadeks) on sarnane teiste ametlike telefonikõnede omaga. Kõne algab rituaalse osaga, kus osalejad tervitavad ja tutvustavad ennast. Sellele järgneb põhiosa, milles toimuvad läbirääkimised. Kõne lõpeb jälle rituaalse osaga, kus vestlejad tänavad ja jätavad hüvasti.

Konsultandid on läbinud enne läbirääkimiste alustamist koolituse, kus on kasutatud firmas väljatöötatud materjale. Läbirääkimiste protsessis nähakse ette järgmised faasid: 1) ettevalmistus, 2) müügiläbirääkimiste avamine, 3) kliendi kaardistamine, 4) argumenteerimine, 5) otsuse saavutamine, 6) jätkutegevus (Vellerind 1998, Rääbis, Vellerind 2000).

Esimene, ettevalmistav faas leiab aset enne esimest telefonikõnet potentsiaalsele kliendile. Konsultant püüab hankida võimalikult palju infot kliendi kohta: asutuse taust, finantsolukord, töötajate arv jms. Viimane faas (jätkutegevus) toimub pärast seda, kui klient on juba osalenud treeningkursusel: siis helistab konsultant kliendile uuesti ja uurib tema hinnangut kursuse kohta. Võimalusel püüab ta äratada kliendi huvi teistegi kursuste vastu. Siin kasutatud korpuses ei leidu selliseid telefonikõnesid, mis käsitleksid jätkutegevusi. Seega saab dialoogides tuvastada faase 2 kuni 5 .

Avamisfaasis esitleb konsultant ennast ja oma firmat. Ta püüab luua positiivset atmosfääri, motiveerida klienti suhtlema, äratada/suurendada tema huvi koolituskursuste vastu.

Kliendi kaardistamise faasis esitab konsultant rea küsimusi, et koguda infot kliendi tegelike vajaduste kohta. Konsultant käitub väga viisakalt ja kannatlikult, laseb kliendil rääkida, talle vahele segamata.

Argumenteerimisfaasis esitab konsultant mõjukaid argumente, mis võtavad arvesse kliendi vajadusi. Kasutatav strateegia on järgmine. Kõigepealt määrab konsultant kliendi jaoks olulised tegurid ja toob need esile, et mõjutada klienti otsustama teatava kursuse kasuks. Kui klient nõustub nende teguritega, siis näitab ja tõestab konsultant, et pakutav kursus lahendab kliendi probleemi. Lõpuks peaks klient nõustuma konsultandi tõestuskäiguga. 
Otsuse saavutamise faasis on konsultandi eesmärk, et klient jõuaks otsusele koolituskursuste suhtes. Otsus võib olla nii positiivne kui ka negatiivne, samuti võib otsustamise edasi lükata. Viimasel juhul lepivad vestlejad kokku järgmise kontakti aja.

\subsection{Müügivestluse lineaarse struktuuri tuvastamine}

Nagu eespool mainitud, on käesolevas artiklis vaatluse all 9 müügivestlust. Üks vestlus jäeti edasisest analüüsist välja, sest selles selgus, et konsultant helistas valel numbril. Ülejäänud 8 kõnet saab jaotada kahte rühma: konsultant ja klient 1) suhtlevad esmakordselt (üks kõne), 2) on olnud kontaktis juba varem (seitse kõnet). Mõlemal juhul on tegu pikkade vestlustega, kõne keskmine pikkus on 93 vooru.

Uurimuse eesmärgiks on leida markerid müügivestluse erinevate faaside tuvastamiseks, et sõnastada reeglid nende automaatseks määramiseks dialoogides, kus on märgendatud DA-d. Selgub, et üldiselt saab kõneluste struktuuri tuvastada DA-de naabruspaaride alusel.

\subsubsection{Avamine}

Iga kõnelus algab rituaalse osaga, kus osalejad tervitavad teineteist (näide 2; $A$ konsultant, $B$ - klient; kasutatud on vestlusanalüüsi transkriptsiooni; dialoogides on märgendatud DA-d).

(2) A: te:re päevast. | RIE: TERVITUS |

B: $£$ tere? $£ \mid$ RIJ: TERVITUS |

Konsultant esitleb ennast ja koolitusfirmat (3).

(3) A: siin on `Asta=Topelt (.) 'Tiritammest. | RY: EsITLus |

((mikrofoni surin)) `koolitus ja konsultatsiooni firmast. | IL: TÄPSUSTAMINE |

B: jah? | VR: JÄTKAJA: NEUTRAALNE |

Konsultant identifitseerib vastuvõtja (4) ja/või avaldab soovi rääkida teatud isikuga, kasutades kas direktiivi või küsimust (5). Sellised DA-de järjendid on telefonivestlustes üsna tüüpilised (Kasterpalu 2006).

(4) A: .h Minna: Patrak kuuleb. | KYE: VASTUST PAKKUV | | RIE: IDENTIFITSEERIMINE | B: $£$ j:ah? $£$ | KYJ: JAH | | RIJ: IDENTIFITSEERIMINE |

(5) A: ja kas ma `saaksin Aigar `Juur- `Juur:seljaga rääkida. | KYE: SULETUD | | RIE: SOOV RÄÄKIDA |

B: jaa | KYJ: JAH |

ma `kuulen. | RIJ: NÕUSTUMINE |

Müügivestlustes võib esineda veel üks rituaalne tegevus - viitamine eelnevale kõnelusele. Konsultant meenutab kliendile eelmist telefonikõnet (6). 
(6) A: mt vestlesime teiega:: (...) mt tetsembri lõpul, mt | SEE: VÄIDE |

(.)

B: täiesti `õige. | SEJ: Nõustumine |

A: jaa: (.) lubasin teile saata ka:: (.) m:aterjalid, mt | SEE: väıDE |

B: jaa. | SEJ: NõUSTUMINE |

$A$ esimene dialoogiakt SEE: vÄIDE pärast tervitusrituaale viitab eelmisele kõnelusele.

\subsubsection{Kliendi vajaduste kaardistamine}

Kaardistamise faasis esitab konsultant rea küsimusi, selleks et koguda infot kliendi vajaduste kohta $(7,8)$. Konsultant käitub äärmiselt viisakalt ja vaoshoitult, innustades klienti rohkem rääkima.

(7) A: /---/

.h mis teil muidu `sellel aastal need `peamised `suunad on. | KYE: AVATUD | (0.5)

B: $£$ no meil mi- `enne meil oli ainult ütleme `metallimüük aga nüüd meil juba siss =ee (.) ämn=ä `kauplus ja `jää ja `hulgimüük ee `tööriistad ja siss ee (0.5) see on nagu jälle noh `uus `suund meil. $£$ | KYJ: INFO ANDMINE |

(8) $\mathrm{A}: /---/$

(3.0) .mt ja `palju teil `on inimesi firmas. | KYE: AVATUd |

B: ehh he `hetkel (2.2) kuus. | KYJ: INFO ANDMINE |

Selles faasis leiab aset info jagamine, $A$ esitab küsimusi ja $B$ vastab, andes infot oma asutuse kohta.

\subsubsection{Argumenteerimine}

Argumenteerimisfaasis esitab konsultant võimalikult mõjukaid argumente koolituskursuste kasuks, võttes arvesse kliendi vajadusi. Argumendid ja vastuargumendid on tavaliselt vormistatud kui väited, mida suhtluspartner võib kas aktsepteerida või tagasi lükata (9).

(9) A: /---/

(1.0) .hh sest loomu 'likult et=ee `töökogemuste kaudu: õpib ka: alati aga .hh a `sageli ongi just `see (0.5) mt ee `kursused pakuvad sellise `võimaluse kus saab siis `teiste .hh oma hh `ala `spetsia `listidega samuti `kokku=ja `rääkida nendest `ühistest prob `leemidest ja samas siis ka .hh ee `mõtteid ja `ideid ee hh ee=`Tiritamme poolt sinna `juurde. | SEE: VÄIDE |

(.)

B: $£$ ¡jah? | SEJ: NÕUstumine |

Paljudel juhtudel toimub argumenteerimine siiski üksikaktide abil (YA: INFO ANDMINE). Konsultant esitab fakte oma koolitusfirma kohta, mis osutuvad argumentideks kursuste kasuks, ja klient annab tagasisidet (10). 
(10) A: /---/

(o.5) .hh et=et `siis loomu `likult=et .hh ee `tegelikult=ee: see ee millised 'valdkonnad nüd 'Tiritamm `pakub on `ka: > .h me oleme just orien`teeritud sellistele `lühikestele. < | YA: INFO ANDMINE |

(0.5) [mt] | YA: MUU |

B: [ $£$ jah? $£$ ] VR: JÄTKAJA: NEUTRAALNE |

A: inten `siiv`kursustele [et] kus saab siis võimalikult palju | YA: INFO ANDMINE

B: $[£$ jah, $£]$ | VR: JÄTKAJA: NEUTRAALNE |

\subsubsection{Otsusele jõudmine}

Otsuse saavutamise faasis on konsultandi eesmärk, et klient teeks otsuse kursuste kohta. Otsus võib olla kas positiivne või negatiivne, kuid kõige sagedamini lükkub analüüsitud kõnedes kursuse tellimine edasi ja osalejad lepivad kokku suhelda hiljem. Konsultant kasutab avatud küsimust või pakkumist, mis sisaldab ajaväljendi (nt millal, selle nädala lõpus, mõne aja pärast, näited 11, 12).

(11) A: hh aga: (.) `kudas te `arvate=et millal=ee saame `rahulikult ee `rääkida nüüd hh ee `personali poole pealt. | KYE: AVATUD |

(12) A: mt ee ja siis `võtan juba=m mnee `mõne aja pärast uuesti `ühendust kui te olete saanud 'tutvuda:. | DIE: PAKKUMINE |

B: $£ \mathrm{j}:$ ah. | DIJ: NõUSTUMINE |

(.) võib `olla `jah. $£$ | DIJ: PIIRATUd NõUSTUMINE |

Analüüsitud dialoogides on kliendi otsus ühel juhul negatiivne ja ülejäänud juhtudel lepitakse kokku suhelda sel teemal edaspidi.

\subsubsection{Sulgemine}

$A$ lõpetab telefonikõne, soovides partnerile $B$ kõike head (13), ning osalejad jätavad hüvasti (14). Selle osa automaatseks tuvastamiseks saab tugineda rituaalsetele DA-dele.

(13) A: /---/

.hh ja `seniks=ee `soovin teile mt (o.2) ee `kena kevadkuu `jätku=ja: nüüd on 'ilmad läinud ka: (0.5) ilusamaks=et | RIE: SOOvimine |

B: $£$ \$ suur tänu? \$ £ heh | RIJ: TÄNAN |

(14) A: `jääme `kuulmiseni. | RIE: TERVITUs |

B: > kõike ead. < | RIJ: TERVITUS | 


\subsection{Parandussekventside tuvastamine}

Dialoogi põhiosas võivad esineda kõrvalekalded "pealiinist" (nn alamdialoogid). Üks alamdialoogide liik on parandused, mida vestlusanalüüs nimetab partneri algatatud parandusteks: üks osaleja algatab paranduse ja tema partner viib selle läbi. Märgendatud dialoogides on sellistel lausungitel topeltmärgendid: üks märgendustase sisaldab spetsiaalseid akte paranduse algatamiseks (PPE: ÜMBERSÕNASTAMINE, PPE: ÜLEKÜSIMINE, PPE: MITTEMÕISTMINE), paranduse läbiviimiseks (PPJ: PARANDUS) ja (ainult mõnikord esinevaks) paranduse hindamiseks (üksikakt vR: PARANDUSE HINDAMINE). Nende märgendite abil on parandussekventse hõlbus tuvastada $(15,16)$.

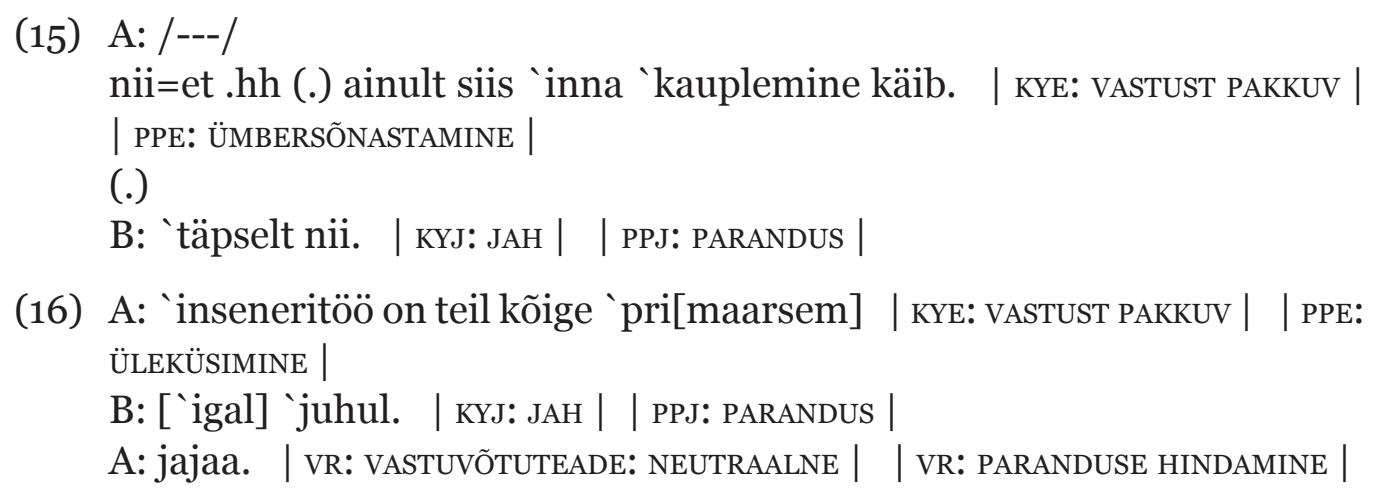

\section{Arutelu}

Korpuse analüüsi tulemusel võib väita, et müügivestluse erinevate faaside tuvastamise põhilisteks markeriteks saavad olla DA-de naabruspaarid.

Rituaalne algus ja rituaalne lõpp on tuvastatavad rituaalsete DA-de naabruspaaride ja üksikakti RY: ESITLEMINE abil vastavalt dialoogi alguses ja lõpus. Konsultandi $A$ esimene seisukohavõtuakt SEE: väIDE vahetult pärast avamisfaasi viitab eelmisele kõnele samade osalejate vahel (juhul kui see on toimunud).

Kliendi vajaduste selgitamine leiab enamasti aset müügivestluste varases staadiumis. Konsultant esitab küsimusi (tüüpiliselt on need avatud küsimused) ja kogub sel viisil infot kliendi asutuse kohta. Küsimuste-vastuste ahel võib olla pikem kui üks naabruspaar, sõltuvalt sellest, kui kaugele on juba arenenud läbirääkimised eelmistes kõnelustes. Algusetapil esitab konsultant rohkem küsimusi, sest siis ta ei tea kliendi vajadustest veel eriti palju. Selle faasi lõpus teeb ta kliendile ettepaneku valida teatud kursus.

Müügivestluse tähtsaim osa on argumenteerimine. Analüüs näitab, et konsultandid käituvad väljapeetult ja piirduvad enamasti info andmisega koolitusfirma kohta. Siiski võib ka sellisel suhteliselt neutraalsel viisil edastatud infot vaadelda kui argumenteerimist teatavate kursuste kasuks. See osa ei sisalda tüüpiliselt DA-de naabruspaare, vaid konsultant annab infot üksikaktide YA: INFO ANDMINE abil ja klient vastab kas vastuvõtuteate või jätkajaga. Mõnel juhul on konsultandi argumendid esitatud kui väited (SEE: VÄIDE), millele klient vastab kas nõustumise või mittenõustumisega (SEJ: NÕUSTUMINE, SEJ: MITTENõUSTUMINE). Argumente saab eristada eelmisele vestlusele viitamisest nende asukoha alusel dialoogis. Võib täheldada, et analüüsitud dialoogides kliendid enamasti nõustuvad konsultandi väidetega, mis 
tähendab, et nood suudavad leida "õigeid" väiteid. Argumenteerimine on müügidialoogi kõige pikem faas.

Kliendi vajaduste uurimine ja koolituskursuste kasuks argumenteerimine võivad toimuda ka vaheldumisi. Ettepaneku tellida kursus teeb konsultant kliendile enamasti kaudsel viisil, vältimaks negatiivset reaktsiooni, nt kas te oleksite huvitatud nendest kursustest. Oodatud ja loomulik vastus on jah.

Tüüpiliselt ei võta klient otsustusfaasis vastu koolituskursuse ostuotsust, vaid osalejad lepivad kokku edasise suhtlemise osas. See pole üllatav, sest nagu öeldud, kuuluvad korpuses leiduvad dialoogid läbirääkimiste algusetappi. Analüüsitud dialoogidest lõpeb ainult üks kliendi resoluutse keeldumisega nii kursustest kui ka edasisest kontaktist. See osa eelneb vahetult kõneluse sulgemisele ja algab tüüpiliselt konsultandi $A$ avatud küsimusega tulevase kontakti kohta.

Pärast mõningate DA-de destilleerimist (Jönsson, Dahlbäck 200o) võib müügivestluse lineaarse struktuuri esitada järgmisel viisil.

[(1) Avamine]

A: RIE: TERVITUS B: RIJ: TERVITUs [A ja B tervitavad]

A: RY: ESITLEMINe [A esitleb ennast]

A: RIE: IDENTIFITSEERIMINE B: RIJ: IDENTIFITSEERIMINE / A: RIE: SOOV RÄÄKIDA

B: RIJ: NÕUstumine [A identifitseerib B]

A: SEE: VÄIDE B: SEJ: NõUSTUMINE [A viitab eelmisele kontaktile (juhul kui see on toimunud)]

[(2) Kliendi vajaduste kaardistamine]

A: KYE: AVATUD B: KYJ: INFO ANDMINE [A esitab küsimusi ja B vastab (võib korduda)]

A: KYE: SULETUD / DIE: ETTEPANEK [A teeb B-le ettepaneku võtta kursus]

[(3) Argumenteerimine]

A: YA: INFO ANDMINE / A: SEE: vÄIDE [A annab infot või väidab midagi koolitusfirma kohta (võib korduda)]

[(4) Otsuse saavutamine]

A: KYE: AVATUD B: KYJ: INFO ANDMINE /A: DIE: PAKKUMine B: DIJ: NÕUSTUMINE [A ja B lepivad kokku jätkata suhtlemist]

[(5) Sulgemine]

A: RIE: SOOVIMINE B: RIJ: TÄNAN

A: RIE: TERVITUS B: RIJ: TERVITUs [hüvastijätt]

Partneri algatatud parandused võivad esineda kõneluse põhiosa suvalises kohas (2. kuni 4. faasis). Parandusi võib algatada nii konsultant kui ka klient.

\section{Kokkuvõte ja edasine töö}

Artikli eesmärk on uurida dialoogi struktuuri, mille moodustavad mikrotaseme üksused - dialoogiaktid ja nende järjendid. Empiirilise materjalina kasutatakse ühte juhuslikult valitud osa müügivestluste korpusest (9 dialoogi). Suhtlejateks on koolitusfirma konsultant ja teise asutuse esindaja (nn klient), kelle kompetentsi kuulub oma asutuse töötajate täiendõpe. Konsultandi eesmärgiks on, et klient otsustaks tellida mõne koolitusfirma pakutavatest kursustest. Dialoogid on salvestatud 
autentses situatsioonis ja litereeritud, kasutades vestlusanalüüsi transkriptsiooni. Tekstides on märgendatud dialoogiaktid, samas ei ole läbi viidud morfoloogilist ega süntaktilist analüüsi. Seetõttu otsitakse dialoogides DA-de järjendeid, mis markeerivad müügivestluse erinevaid faase: 1) avamine, kus konsultant esitleb ennast ja oma firmat, 2) kliendi vajaduste kaardistamine, mille käigus toimub küsimus-vastusdialoog konsultandi ja kliendi vahel, 3) argumenteerimine, kus konsultant esitab mitmesuguseid argumente oma firma kursuste kasuks, võttes seejuures arvesse kliendi tegelikke vajadusi, 4) otsuse saavutamine, 5) sulgemine. Dialoogide analüüsi tulemusel saab sõnastada reeglid müügivestluste erinevate faaside tuvastamiseks, võttes arvesse DA-de naabruspaare ja nende järjendeid ning positsiooni dialoogis. Tulevane töö seisneb automaatse pragmaatilise analüüsi tarkvara arendamises, mis võimaldaks tuvastada dialoogides nii dialoogiakte kui ka aktijärjendeist moodustuvat lineaarset struktuuri ja alamdialooge.

\section{Viidatud kirjandus}

Aller, Sven 2012. Dialoogiaktide tuvastamine Eesti dialoogikorpuses: ülevaade ressurssidest ja tarkvaraarendus. Magistritöö. Tartu Ülikooli arvutiteaduse instituut. http://comserv. cs.ut.ee/forms/ati_report/ (27.09.2012).

Barton, Ellen 2004. Linguistic discourse analysis: How the language in texts works. - Charles Bazerman, Paul Prior (Eds.). What writing does and how it does it: An introduction to analyzing texts and textual practices. Mahwah N.J.: Lawrence Erlbaum Associates, $57-82$.

Gibbon, Dafydd; Mertins, Inge; Moore, Roger (Eds.) 2000. Handbook of Multimodal and Spoken Dialogue Systems: Resources, Terminology and Product Evaluation. Kluwer Academic Publishers.

Hennoste, Tiit; Rääbis, Andriela 2004. Dialoogiaktid eesti infodialoogides: tüpoloogia ja analüüs. Tartu: TÜ Kirjastus. http://dspace.utlib.ee/dspace/handle/10062/18995 (10.12.2012).

Hennoste, Tiit; Gerassimenko, Olga; Kasterpalu, Riina; Koit, Mare; Rääbis, Andriela; Strandson, Krista 2009. Suulise eesti keele korpus ja inimese suhtlus arvutiga. - Eesti Rakenduslingvistika Ühingu aastaraamat, 5, 111-130. http://dx.doi.org/10.5128/ERYa5.07

Hutchby, Ian; Wooffitt, Robin 1998. Conversation Analysis. Cambridge: Polity Press.

Jönsson, Arne; Dahlbäck, Nils 2000. Distilling dialogues - A method using natural dialogue corpora for dialogue systems development. - Proceedings of the 6th Applied Natural Language Processing Conference, Seattle, 44-51.

Kasterpalu, Riina 2006. Algusrituaalid müügikõnedes. - Mare Koit, Renate Pajusalu, Haldur Õim (toim.). Keel ja arvuti. Tartu Ülikooli üldkeeleteaduse õppetooli toimetised 6. Tartu: Tartu Ülikooli Kirjastus, 156-169.

Lester, J.; Branting, K.; Mott, B. 2004. Conversational Agents. - Munindar P. Singh (Ed.). The Practical Handbook of Internet Computing. Chapman \& Hall, 220-240.

Rääbis, Andriela; Vellerind, Riina 200o. Müügiläbirääkimised kui institutsionaalne dialoog. Tiit Hennoste (Toim.). Eesti keele allkeeled. Tartu Ülikooli eesti keele õppetooli toimetised 16. Tartu: Tartu Ülikooli Kirjastus, 148-173.

Vellerind, Riina 1998. Suulise vestluse struktuur telefoni teel peetud müügiläbirääkimiste näitel. Bakalaureusetöö. Tartu Ülikooli üldkeeleteaduse õppetool.

Mare Koit (Tartu Ülikool) on uurinud dialoogi modelleerimist arvutil.

mare.koit@ut.ee 


\section{HOW TO RECOGNISE THE DIALOGUE STRUCTURE: CORPUS ANALYSIS}

\section{Mare Koit}

University of Tartu

The aim of this study is to determine the dialogue structure formed by microlevel units - dialogue acts. The empirical material of the study is a small part (nine human-human dialogues) of a corpus consisting of telemarketing calls. In the calls communication takes place between business representatives on a win-win basis, which means that the caller (a sales clerk of an educational company) is offering a competence, supposedly needed by the receiver (a customer). Dialogues are recorded in authentic situations and then transliterated using the transcription of conversation analysis. Dialogue acts (DA) are annotated in the transcripts but neither syntactic nor semantic analysis is performed. The study investigates DA markers which would help to identify the phases of a telemarketing call: 1) the opening, where a sales clerk introduces himself and the educational company, 2) explanation of the needs of a customer where question-answer dialogue takes place between a clerk and a customer, 3) argumentation where several arguments for taking a course are presented by a clerk, taking into account the actual needs of the customer, 4) coming to a decision. Rules for recognition of the structure of telemarketing calls will be formulated on the basis of sequences of (adjacency pairs of) dialogue acts and their position in a dialogue. A further aim is to implement software for automatic pragmatic analysis of the calls in order to recognise dialogue acts, sub-dialogues, and the linear structure of dialogues.

Keywords: dialogue, telemarketing call, dialogue structure, dialogue act, Estonian 